\title{
How to Maximize Earnings by Using Financial Risk Management in the United States During Coronavirus Pandemic
}

\author{
Deng Siyuan $^{1, *}$ \\ ${ }^{1}$ School of Business Administration, Southwestern University of Finance and Economics, Wenjiang, Chengdu, \\ Sichuan, Peoples R China \\ *Corresponding author: Deng Siyuan. Email: siyuandeng0327@163.com
}

\begin{abstract}
This research report will focus on the question that: how to maximize earnings by using financial risk management in the United States during Coronavirus Pandemic. The whole essay will be divided into 3 parts. And those are just the three research questions. The researcher will discuss the pandemic's impact on the U.S. domestic stock market and the main environmental and behavioral factors that cause the economic recession of America first. Then the researcher will go to the section about What action did the FRS take to save the American collapsing financial stock market in the past half year? What was its purpose and effect? The third part, in which the researcher will focus on some potential tools to maximize our earnings, is followed by the prediction and commendation of some promising stocks. The topic is not only a research for the present situation, but also for the future. It can uncover the law and the trend of the changing risk management style. And then the researcher can conclude its traits and make predictions about the future. The world nowadays is really a dynamic and unstable. To some extent, risk management differ from country to country. This essay can help us to figure out what can we adopt to gain profit during the pandemic and give out the solution to how to make a plan to find such useful tools. The materials are very novel, including a lot of realistic international background cases. The researcher properly draws on the views of those honored predecessors and researcher then establishes his own theoretical system on the basis of traditional management views. So, the essay can demonstrate some typical but new ideas to strengthen the credibility of my perspective. The methodology are mostly mixed and descriptive. The researcher has found that Technology stocks, Biomedical stocks, Online business stocks and Food industry stocks are suitable to invest, especially the five giant corporations: Facebook, Visa, Microsoft, Amazon, and Apple. Inc.
\end{abstract}

Keywords: Risk Management Styles, Financial Crisis, US Stock Market

\section{INTRODUCTION}

\subsection{Background and Context}

This year-2020, the outbreak of the corona virus has caused a severe damage to the financial market. Take the stock market of the United States as an example. There is much uncertainty there. Actually, some economists are not so optimistic about the current world market and they are very concerned about the possibility of the worldwide economic recession. Leaders have to be fully prepared for the incoming crisis of any aspect. So, the question for all the investors to take in consideration is oriented to the risk control. To avoid risk and maximize earnings, we need to find out a new way to go. What should investors do at such a tough time to face such a disaster? It definitely requires the investors to have a kind of willingness and capabilities to change his risk management style. By then, the financial market can get an opportunity to thrive again. I tend to look closely at the daily operation of financial markets in different areas around the globe and analyze the data to work out a general rule for it. So, by researching the topic, we can uncover some useful and effective way to manage and control financial risk. No matter you are an investor or a leader of a corporation, it is very important to know how to employ financial risk management to maximize your earnings. It has a significant meaning to forecast the best future portfolio. 


\subsection{Proposed Research Questions}

1.What are the main environmental and behavioral factors that cause the economic recession of the U.S.A during the Coronavirus Pandemic?

2.What action did the FRS (Federal Reserve System) take to save the American collapsing financial stock market in the past half year? How about the effect?

3.As American individual investors, with financial risk management, how to make an investment to maximize our incoming during this special period?

\section{LITERATURE REVIEW AND SIGNIFICANCE}

Recently, the world financial market especially the stock market has been severely hit by the chaos around the globe.

Mean while, more and more researchers start to do the relevant research. As a result that the coronavirus spread across all countries, a majority of the investors face their portfolios painted in a red ink, even though there are still opportunities to gain from the current pandemic situation [3].( Diana Tashanova, Ainur Sekerbay, Danni Chen, Yuwen Luo, Shuyi Zhao, Qingquan Zhang.2020) Also, the situation of the capital markets, generated by the uncertainty looming over the management of the effects of the coronavirus pandemic, reflected in the decisions of the governments around the world, can affect investors' portfolios, leading to major losses [1]. (Florin ILIE,2020) And Unfortunately, if this happens, it is very difficult to start while having to recover these losses. Because of it, the risk of investment has gone up. As usually we know, if the stock market is riskier, it means that you have more chances to gain more profit. Modern portfolio theory shows that specific risk can be removed or at least mitigated through diversification of a portfolio [2]. The biggest risk is when there is no risk" (Opran, Stan, Abaza \& Nastasa, 2002). It is time for the investors in the U.S. to change their financial risk management style. But in practice, risk management is very confusing for normal investors.

Still, some researchers (Ben Mcclure, etc.) have described the behaviors of different kinds of people to analyze the collapsing financial market [2]. Researchers often adopt qualitative methods to focus on one specific area to get further understanding and then express their own ideas. Although their academic fields may vary a lot, they still conduct a series of new outcome for us to do further study.

However, most of the researchers have not come up with some new methods to maximize the earnings in the stock market of the U.S. during the pandemic because the problem is very new. But there are still some of the researchers have given out 6 their prediction about the trend of the financial stock market in the United States. According to their findings, all the promising stocks should be divided into two parts which are long-run part and short-run part. These two are totally distinct. To gain the long-run profit, you need to be more patient. The impact of the outbreak is vital for the financial change. We need to wait until the side effects disappear. But the short run is different. We should take the present financial environment into consideration which is unstable and difficult to achieve.

As ordinary people, researchers suggested that we can adopt the Dollar Cost Averaging (DCA) which works for all investments. Dollar cost averaging (DCA) is an investment strategy that may be used with any currency. It takes the form of investing equal monetary amounts regularly and periodically over specific time periods (such as $\$ 100$ monthly for 10 months) in a particular investment or portfolio.

In the research, to fill in the gaps, the researcher will work out several ways for the normal American investors to increase their profit at most. Following their steps, I will mainly focus on some special specific industries such as Technology industries, Biomedical industries, Online business industries, Food Production industries, etc.

\section{METHODOLOGY}

\subsection{Data Collection}

\subsubsection{Mixed Methods (Both Quantitative and Qualitative)}

As we know, financial market is an area which is usually oriented and dominated by the numbers. All the data about the financial market may relate to numbers. Accordingly, to do the research more precisely and accurately, I tend to use both the quantitative methods and qualitative methods to work out my essay. It is suitable to be used to test or confirm the theories and assumptions. My research problem is "How to maximize earnings by using financial risk management in the United States during Coronavirus Pandemic", which is a topic that requires much more essential 7 data than other problems. I need those quantitative numbers and qualitative theories to analyze the research.

Compared with single methods, my research has the chance to break the limits of concepts and experiences. I have more room to expand my research problem.

\subsubsection{Secondary Data}

I prefer to use the secondary data more than primary date because the topic "financial risk management during Coronavirus Pandemic" is a very new and hot point. It may be difficult for we researchers to do experiments or something else to get the primary data. 
So, I tend to use some secondary data that other have done before by following their timeline of surveys.

However, this does not mean that I will rely entirely on the research of others. I will also try my best to get some primary data. I will talk to my advisor at school to get more new ideas.

\subsubsection{Descriptive Data}

After a moment's thought, I eventually choose to employ descriptive data because it allows me to describe my research subject without influencing it. It will make my essay closer to the reality and remain its logic. What is more, I can gather more data on a large scale. On contrary, experimental data may influence my research subject in an unexpected way and it usually requires more expertise and resources to collect data. It is time-consuming and demanding. I would rather sacrifice the accessibility of data for the objectivity of data.

\subsubsection{Tools}

Besides these methods above, I will still adopt some useful academic tools to continue my study. They are much helpful in the process of essay writing. They will strongly help me to situate my research in an existing body of work, to evaluate trend within a research topic and to gain an in-depth understanding of a specific group or context. (1)

\subsection{Data Analysis}

I eventually choose to apply the meta-analysis to continue my data analyzing. It will be quantitative, qualitative, descriptive and with diverse variables (Categorical Variables and Numerical Variables).

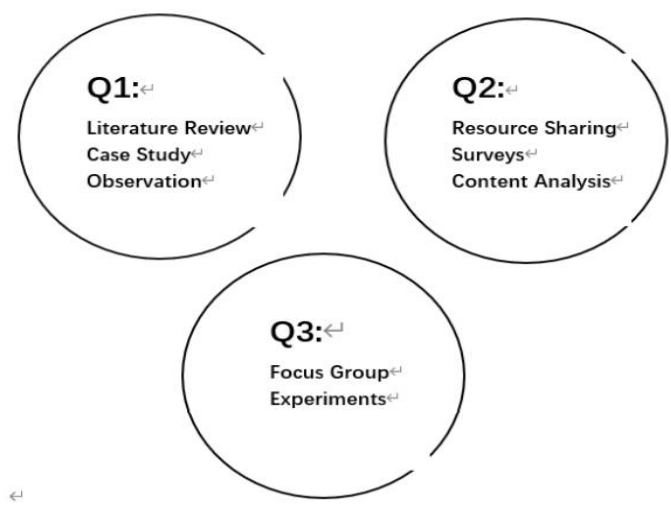

Figure 1. All the methods and tools that adopted in the financial research.

\section{FIGURES AND TABLES}

\subsection{Graphics of Changing Trend of The Stock Markets Around the Globe}

Table 1.Decreased indices in several stock markets in the world (Source: https://finance.yahoo.com)

\begin{tabular}{||c|c|c|r|r|r||}
\hline Index & Country & Curency & $\begin{array}{c}\text { Value at } \\
\mathbf{1 9 . 0 2 . 2 0 2 0}\end{array}$ & $\begin{array}{c}\text { Value at } \\
\mathbf{2 3 . 0 3 . 2 0 2 0}\end{array}$ & Variation \\
\hline \hline S\&P 500 & USA & USD & $3,386.15$ & $2,237.40$ & $-33.92 \%$ \\
\hline DJI & USA & USD & $29,348.03$ & $18,591.93$ & $-36.65 \%$ \\
\hline NIKKEI 225 & JPN & JPY & $23,400.70$ & $16,552.83$ & $-29.26 \%$ \\
\hline DAX 30 & GER & EUR & $13,789.00$ & $8,741.15$ & $-36.61 \%$ \\
\hline FTSE 100 & GBR & GBP & $7,457.02$ & $4,993.89$ & $-33.03 \%$ \\
\hline CAC 40 & FRA & EUR & $6,111.24$ & $3,914.31$ & $-35.95 \%$ \\
\hline ATX & AUT & EUR & $3,198.33$ & $1,880.82$ & $-41.19 \%$ \\
\hline BET & ROM & LEI & $10,204.97$ & $7,038.95$ & $-31.02 \%$ \\
\hline
\end{tabular}

All the stock markets around the globe have been suffered from the pandemic. People began to lose confidence.

Table 2. The return of the indices value in world stock markets (Source: https://finance.yahoo.com)

\begin{tabular}{||c|c|c|r|r|r||}
\hline \hline Index & Country & Curency & $\begin{array}{c}\text { Value at } \\
\mathbf{2 3 . 0 3 . 2 0 2 0}\end{array}$ & $\begin{array}{c}\text { Current value } \\
\mathbf{2 2 . 0 5 . 2 0 2 0}\end{array}$ & Variation \\
\hline \hline S\&P 500 & USA & USD & $2,237.40$ & $2,955.45$ & $32.09 \%$ \\
\hline DJI & USA & USD & $18,591.93$ & $24,465.16$ & $31.59 \%$ \\
\hline NIKKEI 225 & JPN & JPY & $16,552.83$ & $20,388.16$ & $23.17 \%$ \\
\hline DAX 30 & GER & EUR & $8,741.15$ & $11,073.87$ & $26.69 \%$ \\
\hline FTSE 100 & GBR & GBP & $4,993.89$ & $5,993.28$ & $20.01 \%$ \\
\hline CAC 40 & FRA & EUR & $3,914.31$ & $4,444.56$ & $13.55 \%$ \\
\hline ATX & AUT & EUR & $1,880.82$ & $2,127.47$ & $13.11 \%$ \\
\hline BET & ROM & LEI & $7,038.95$ & $8,592.48$ & $22.07 \%$ \\
\hline \hline
\end{tabular}

All most the stock markets are recovering from their pain. The market is starting to pick up. But it is not the time to be optimistic because the risk of the economic recession is still high. 


\subsection{Graphics of Some Promising Stocks}

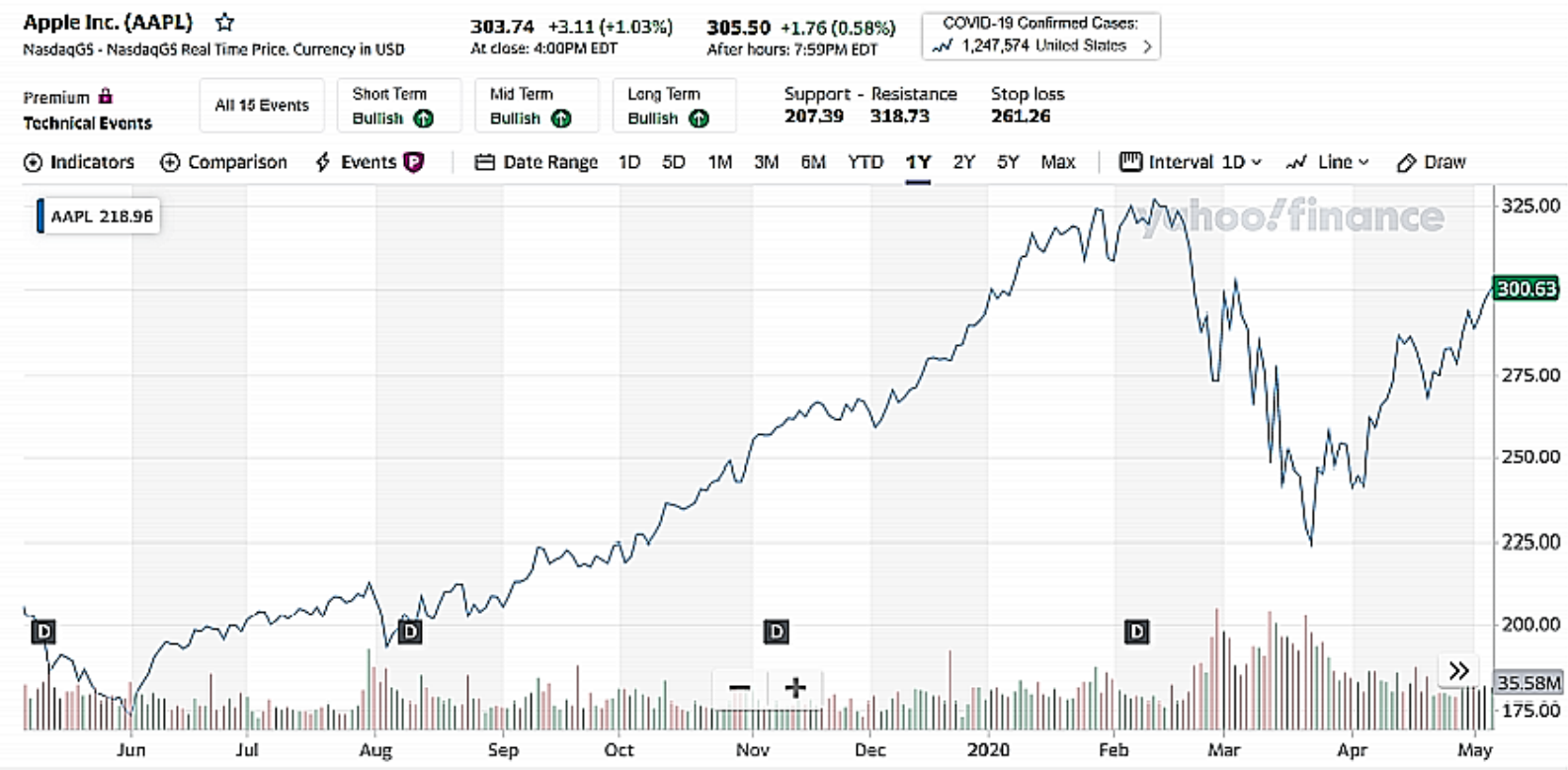

Figure 2. A trend chart showing Apple's stock from May 2019 to May 2020.

Apple Inc. gains a lot after a short term and reaches its peak. Apple has been a trusted company for long. Its share price is one of the most stable face prices in America.

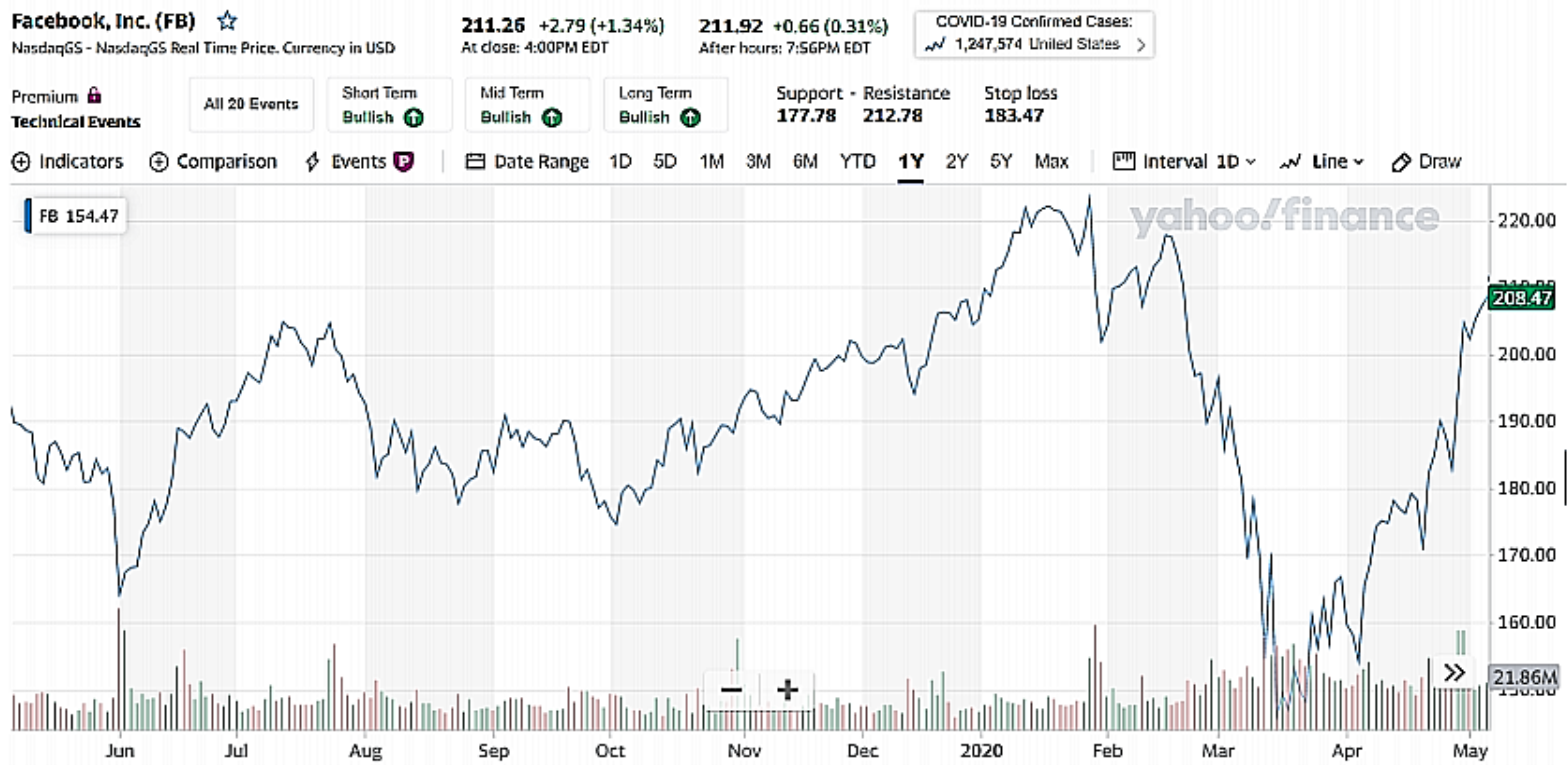

Figure 3. A trend chart showing Facebook's stock from May 2019 to May 2020.

The price of Facebook seems to be unstable. But the line on the graph does show its endurance and vitality.
As one of the best-known online companies in the U.S, Facebook will find its way to develop. 


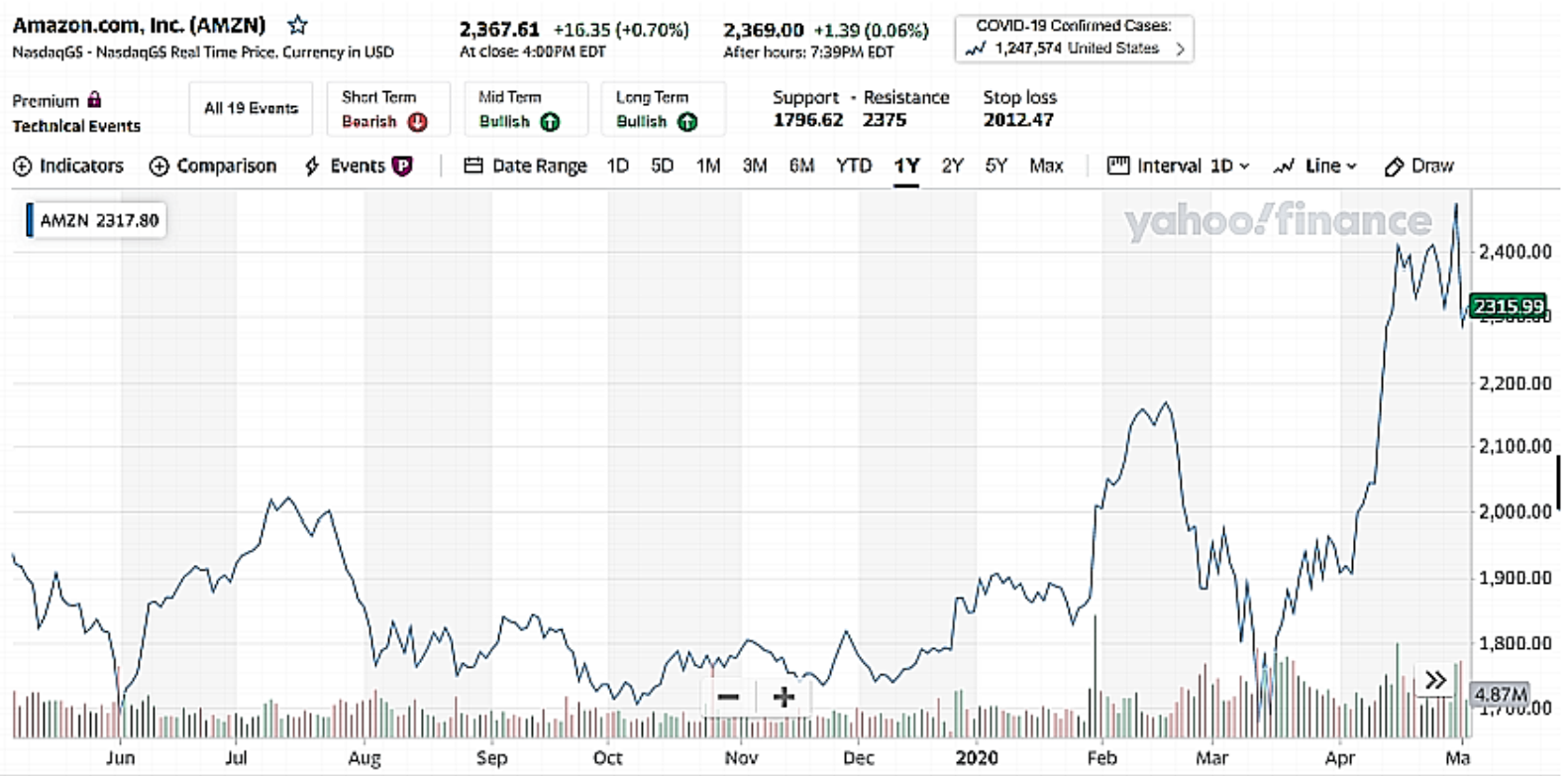

Figure 4. A trend chart showing Amazon's stock from May 2019 to May 2020.

Amazon is extremely charming! Even though there is the fatal pandemic, which is a kind of poison for the trend. Although this mostly results from the expanding stock market, Amazon has still remained its increasing demand of buying or delivering things online, it is still

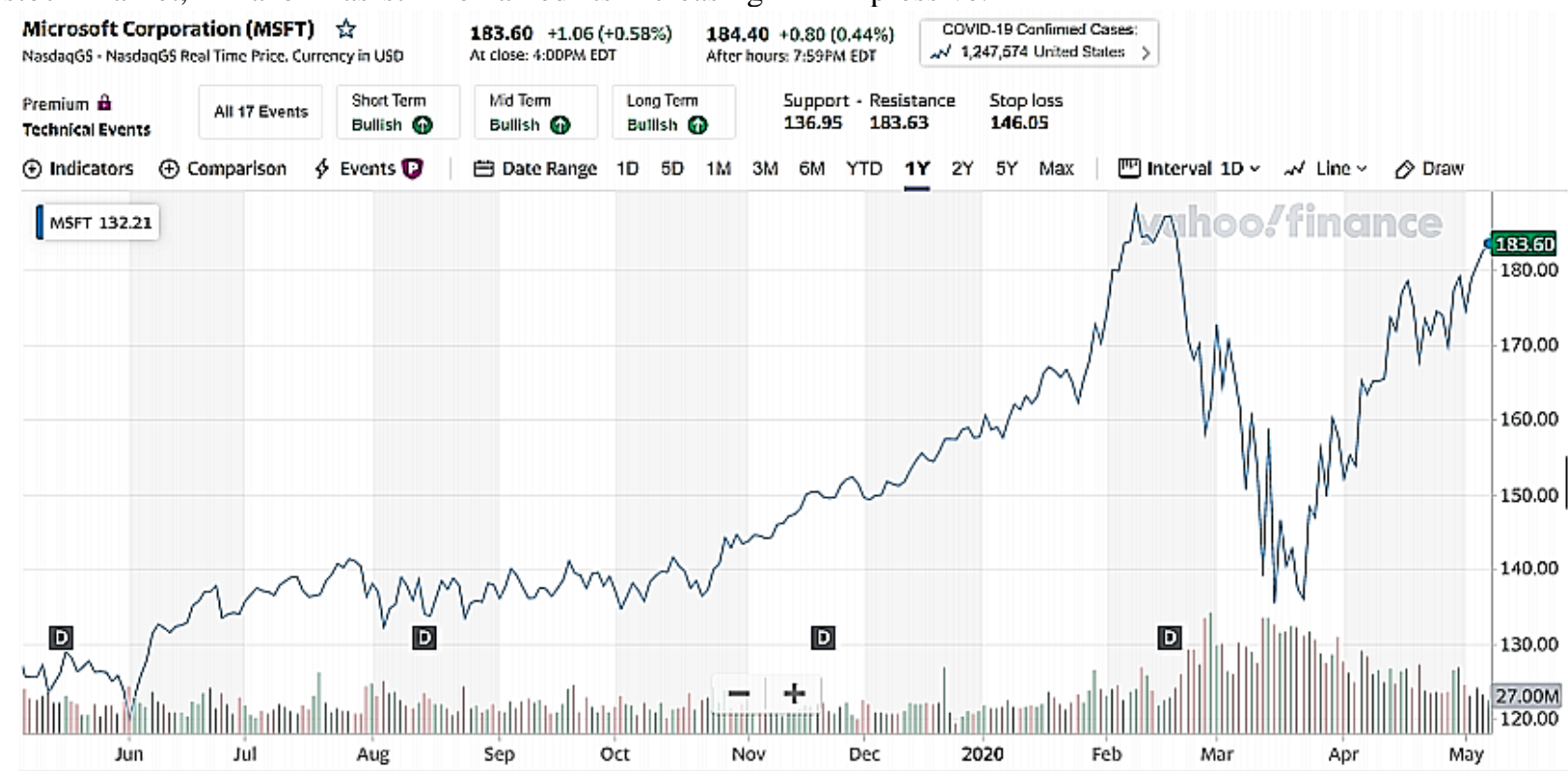

Figure 5. A trend chart showing Microsoft's stock from May 2019 to May 2020.

Twenty years ago, Microsoft (MSFT) was the world's most valuable company. ow that its rivals Apple (AAPL) and Amazon (AMZN) have surpassed its market capitalization, Microsoft will continue to be a major player in markets around the world. The tech sector as a whole has been on an upswing over the past few years, and the $300 \%$ rise in Microsoft's leading company's share price is not exactly an exaggeration. In spite of this, it is always an attractive corporation especially now. 


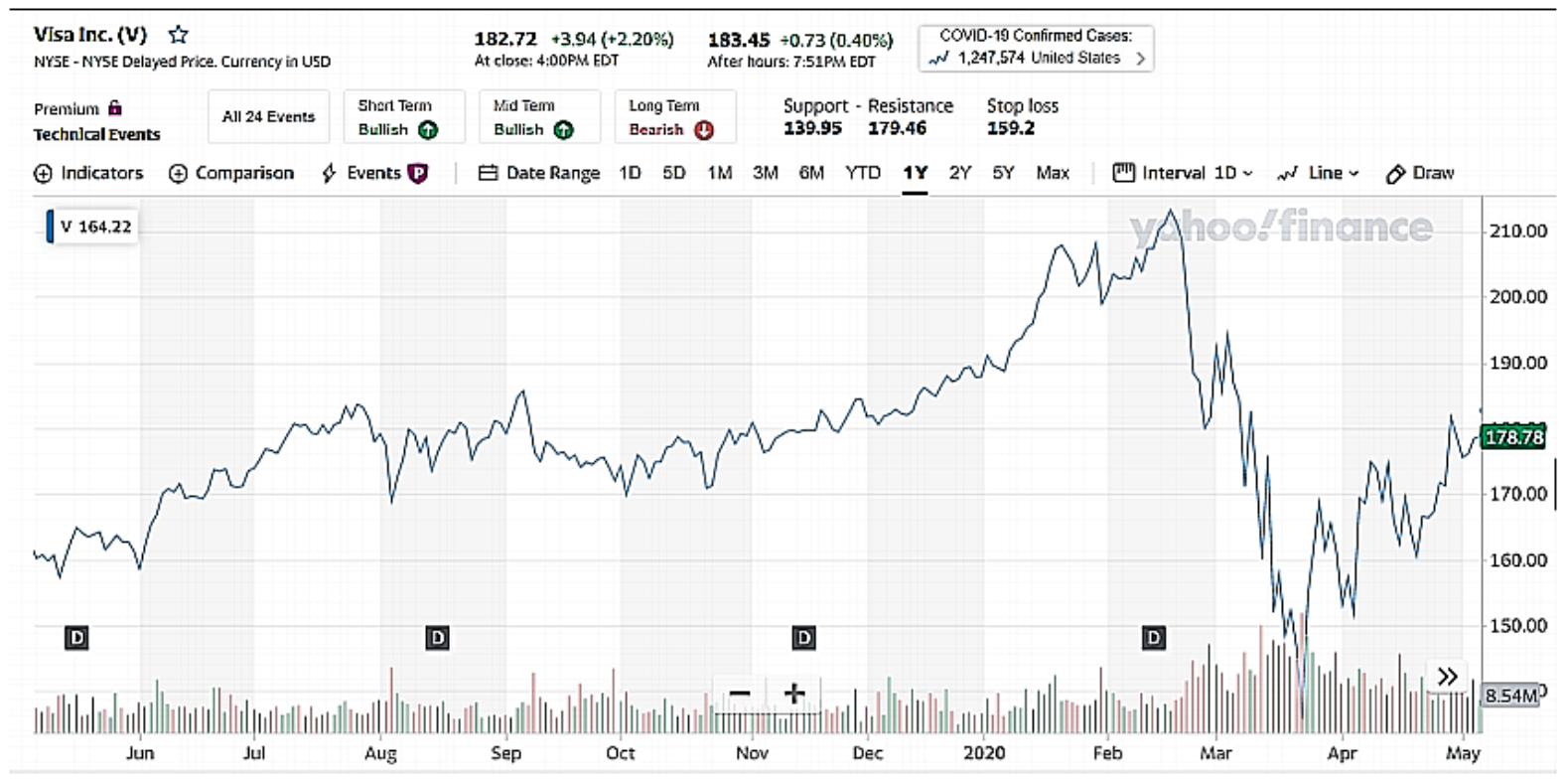

Figure 6. A trend chart showing Visa's stock from May 2019 to May 2020.

As a global card organization, Visa connects consumers, businesses, financial institutions, governments, and merchants in more than 200 countries and regions through a fast and secure electronic payment network to provide them with superior payment methods. That is not hard to explain why its share price has remained high.

\section{DISCUSSION}

\subsection{Proposed Question 1}

With the outbreak of the COVID-19, the American financial market suffered a lot. Since March, the stock market have triggered the circuit breaker mechanism for 4 times. It is a very severe warning for the country. People started to have no patience and confidence to trade. It is the ringing bell of the economic recession.

On March 9, 2020, the New York Stock Market plunged at the opening, and then the decline reached the limit of $7 \%$, which triggered the circuit breaker mechanism. After the resumption of trading, the decline narrowed for a while, and at the close of the New York Stock Market, the three major stock indexes all fell by more than 7\%. On March 12th America's three main stock indices plunged immediately after the opening bell. The Dow plunged more than 1,400 points in the open, while the S\&P 500 fell more than 6\%. Market analysts believe the S\&P 500 could soon fall through the $7 \%$ circuit breaker again, leading to a second 15minute circuit breaker that week. On March 16, the three major US stock indexes opened sharply lower, with the S\&P 500 falling more than 7\%, triggering a circuit breaker that halted trading for 15 minutes. At midday on March 18, the circuit breaker was triggered again by a sharp fall in the New York stock Market.

After analyzing the trend of the American stock market in the history, I find that each plunge in the U.S. stock market is preceded by a distinctive feature: after a long bull market, the stock market rises to the top or around the top. In other words, the U.S. stock market has a bubble before the crash, and the crash is usually 14 accompanied by the bursting of the bubble.

\subsection{Proposed Question 2}

Until the end of March, the situation began to get better. That is because in response, the Federal Reserve embarked on a "nuclear bomb" of quantitative easing, printing unlimited amounts of money (QE5). The US plans a government intervention amounting to \$2 trillion (Megginson and Fotak 2020). This will ease the tension of economic recession. It means the US government has responded to the possible economic repercussions with a variety of financial aid schemes.

Generally, to solve the problems about risk management, experts agree on one aspect: the answer to a viable long-term solution is business flexibility (McKinsey 2018). For this, the unanimously accepted solution is business digitalization (European Investment Bank 2020; McKinsey 2020b). This is what the US government has done in the past half year [5].

According to the QE policy of the FRS, all the behaviors mean the Federal Reserve has formally surrendered to the White House since 2017 with no bottom line on its policy of monetary tightening and interest rate normalization. If these monetary policies sound familiar, it is because it is basically the same script for quantitative easing through 2008. But the 
biggest difference this time is that the Fed has not spent a year doing what it did in 2008. All these policies were adopted in less than a month. Its purpose is to save the US stock market after a huge drop and shift the domestic conflict to the world. It is reminiscent of the 1970s, when the former US Treasury Secretary John Connally famously said, "the US dollar is our currency, but it's your problem!". What he meant was clear: America's monetary policy was based solely on its own interests and was not responsible for the harm done to other countries as a result. It is a cruel thing to say, but it is true.

So far, the Fed has used almost all the tools used during the 2008 financial crisis (except TSLF, TAF and MMIFF), as well as two new liquidity facilities for corporate 15 bonds, PMCCF and SMCCF. Now, with the exception of negative interest rates and the bank of Japan's direct purchase of equity etfs, the Fed has done almost everything it can to pump liquidity into the economy, covering most markets except junk bonds and equities and accommodating the needs of American households, businesses, and financial institutions. Through these almost extreme actions, the Fed hopes to make near-interest-free money readily available to American businesses and private individuals. These measures will undoubtedly quickly blow up the Fed's balance sheet. In fact, the fed's three rounds of QE between the last international financial crisis and 2013 have increased its total assets from about $\$ 1$ trillion in 2008 to $\$ 4.5$ trillion in 2017. As of March 19, the Fed's assets stood at $\$ 5.25$ trillion. If $\mathrm{QE}$ continues at its current pace of $\$ 625 \mathrm{bn}$ a week, the Fed's balance sheet will reach $\$ 10$ tn by June 2020, close to 50 per cent of US GDP in $2019(\$ 21.05 \mathrm{tn})$. In the face of such a massive rescue effort, U.S. stocks on March 24 posted their biggest one-day gain since 1933, with the STANDARD \& Poor's 500 index up $9.38 \%$ [4].

However, the outbreak cannot be brought under control without a temporary shutdown, which would lead to a predictable and temporary economic downturn. In the US, the service sector accounts for 80 per cent of the national economy (compared with 60 per cent in China in recent years). The service sector, a pillar of the US economy, has been hit hard by stringent containment measures. Consumers have been forced into social isolation, retailers, bars, restaurants, cinemas, ball games and other consumer services that rely on foot traffic have been forced to close or shorten their hours, and logistics industries, including airlines, have all but stopped operating. In the United States, for example, 15.8 million people work in the leisure and hospitality industry, which is currently closed because of the outbreak. The US services purchasing managers' index fell from 49.4 to 39.1 in March from the previous month (forecast at 42, compared with 49.4), its lowest level since October 2009, indicating that the sector was already pretty bleak. 16 .
On March 26, the U.S. Department of Labor released data showing that the number of Americans applying for initial jobless benefits in the week of March 21 reached a record 3.283 million (1.7 million expected, up from 281, 000), almost equal to $2 \%$ of the U.S. workforce. The previous record was 695,000 during the 1982 world economic crisis, and only 667,000 during the last global financial crisis. It can be seen that the epidemic has had a serious impact on employment. Economists estimate the unemployment rate will hit 12.8 per cent in the second quarter, up from 3.5 per cent in February and 9.5 per cent in July 2010, during the financial crisis. The longest employment boom in US history could come to an end.

The states with the fastest growth in claims were Pennsylvania, Ohio, and New Jersey. It is unclear whether states have enough reserves to pay for unemployment benefits. Rich California, it is reported, has only 0.21 of a year's reserve of unemployment benefits. Several of the nation's largest states -- Texas, New York, Ohio, and Illinois -- are said to have barely enough money to cope with soaring unemployment. That is why U.S. President Donald Trump wants some businesses in the U.S. to reopen before Easter, April 12. But the current outbreak in the United States may not be moving that fast.

There is no doubt that the US economy will fall into recession. For now, it is only a matter of degree.

\subsection{Proposed Question 3}

Current stock market developments indicate a considerably negative outlook, with the MSCI world index recently recording a drop of over 30 percent in the month following February (Onvista 2020).

Additionally, the International Monetary Fund (IMF) forecasts that the current pandemic will plunge the global economy in the deepest crisis since the Great Depression (FAZ 2020) [5]. Against this backdrop, Gourinchas (2020) mentions that bold policy initiatives are needed to prevent further human contagion, followed by 17 fiscal and financial policies to prevent economic contagion [4].

However, there are still opportunities to gain profit. To face such economic recession, what can the ordinary US investors do to maximize their earnings? People need to change their risk management style(preference) and portfolio.

But the question is: what kind of industries are worth investing? Because of the QE policy, in the second part of the pandemic, the US stock market is healing. From 23.3.2020 to 22.05.2020, the value of S\&P 500 has returned from 2237.40 to 2955.45 . The value of DJI is also recovering from 18591.93 to 24465.16, which reaches the level of the end of 2017. 
The two stock market indexes rose 32.1 percent and 31.6 percent, respectively.

Actually, the rise or fall in the stock market can be seen as a change in investor confidence. So, the more confident the investors are, the higher the value of the stocks is. Combining the current financial surroundings, we can easily do some basic predictions about the future trend. Hence, I suggested analyzing some of the riskier investment options in the U.S. market, and I focused on stocks that had fallen sharply over the period: airlines.

This is just for long-term investment. Risk can often bring profit. Take DAL as an example, the DAL shares went sideways in early 2020, but the unfortunate events that have caused a global stock market panic since February 24 have not bypassed the airline (which paid a dividend of $\$ 0.403$ per share to shareholders a few days ago). The stock has fallen $67.62 \%$ in less than a month, from a high of $\$ 58.99$ on Feb. 20 to a low of $\$ 19.10$ on March 19. Meanwhile, the S\&P 500 index "only" lost $33.92 \%$, less than half the DAL's losses. What is worse, S\&P also cut its rating to "BB" from "BBB-" and the company expects second-quarter revenue to fall by $\$ 10$ billion, or 80 percent from the same period in 2019. In contrast to the situation in the United States and most stock markets around the world, DAL shares continued to fall, hitting a low of $\$ 17.51$ on May 14. At that price, the drop is more than 80 per 18 cent of the value set on February 20. So, as you see, as one of the biggest airline company, the price of DAL has reached its lowest point in the history. Air line industry is a thriving and essential area that no one can live without it. It will definitely thrive again if it does not go bankrupt. But are you willing to take the risk?

About the short-term investment period, I suggest choosing some promising and stable stocks so that all the stakeholders can gain get some profit safely in the short run. The pandemic has killed many people, but it also raised some kinds of requirement such as Technology stocks, Biomedical stocks, Internet stocks, Food industry stocks, etc. They are so closely related to everyone's daily life when all the citizens are asked to be quarantined at home.

Technology is the prime power to innovate, which people have great confidence in it.

The demand of biomedical stuff and supplies has sharply increased. So, the trend of biomedical stocks is positive and optimistic.
During the pandemic, people stayed at home. So, they need to store food which leads to panic buying. This resulted in the higher price of some food production stocks.

After solving the problems about food and meals, people turned to find some fun. Many APPs have gained a massive number of users during this period. People are stuck at home, no chance to hang out or work. Accordingly, those internet corporations are coming up with new products and services to meet people's new needs for telecommuting or entertainment. It is a hot trend.

In a nutshell. no matter what kind of preference you want to finally adopt, (short run or long run), the key point for individual investors to maximize earnings is to change financial risk management by balance risk and profit.

\section{CONCLUSION}

To eliminate the financial risk in the US stock market, I prefer to invest some blue-chip stocks such as Amazon, Apple, Visa, Microsoft, and Facebook. They behaved very well and convincingly. After a short time of decline, these stocks are some of the fastest corporations to recover from their loss. Tack Microsoft as an example, they have even reached its new peak. No matter it is in history or it is at present, blue chip stocks are always the investment resources that you can always trust.

What is more important, all the blue-chip stocks belong to the hot industries that I mentioned above such as technology industry and online business industry. They all got on the right track. The trend is hot, so investors have strong faith in it, so do the price of theses stocks. The effect of the outbreak of the COVID-19 is reducing nowadays. So, the demand of food and remote entertainment are also weakened. So, the investment in the food industry stocks and remote entertainment industry stocks should be very careful.

For the two areas, I recommend Coca Cola Group and Netflix. According to the Berkshire Hathaway's 13F disclosure on June 30,2017, the investment firm held $\$ 400$ million of Coca-Cola Company is the world's largest beverage company and owns four of the world's top five non-alcoholic beverage brands: Coca-Cola, Diet Coke, Fanta, and Sprite, with products sold in more than 200 countries. 


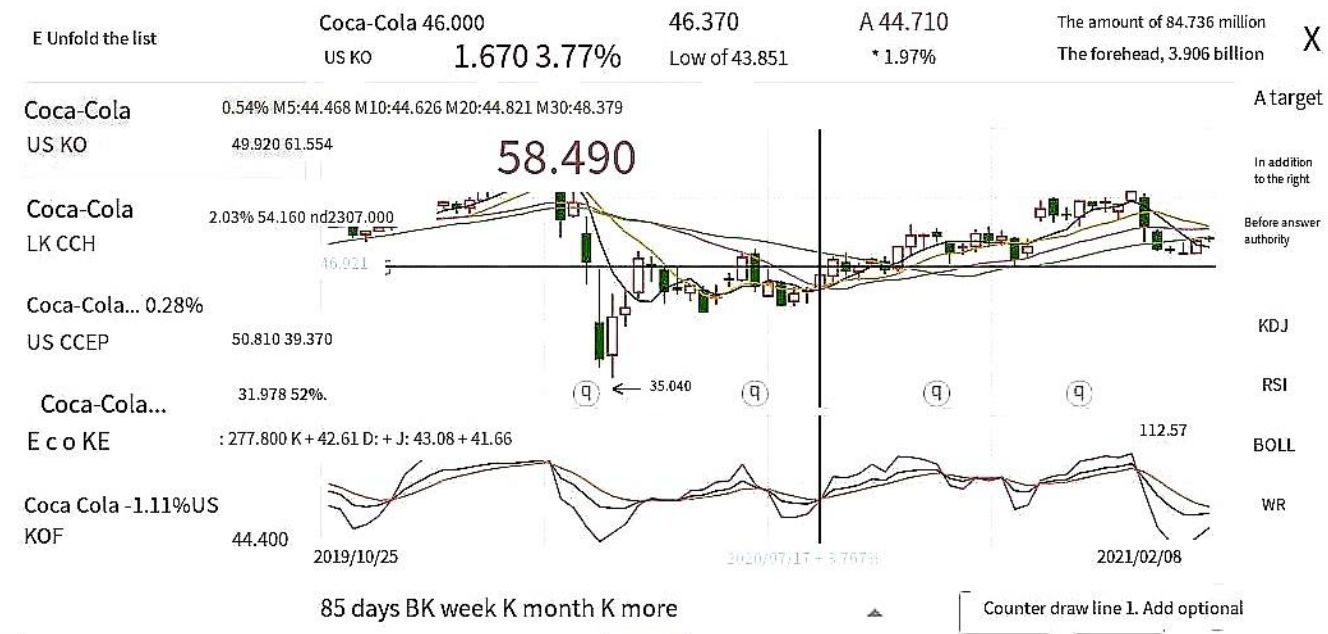

Figure 7. Trend chart for Coca Cola stock from October 2019 to February 2021.

The company's main products are carbonated beverages, as well as water, juice, sports drinks, and energy drinks. Even during the pandemic, the stock stayed steady and rising. And as a leading company in the soft drink industry, the group is facing recombination and cutting its employees off to change its business style around the world. It is probably a good time to purchase its stock. As the graphs above, we can see that there are still many investors are so confident about the future of the company. Forecasts for the appreciation of its share price remain optimistic.

And about Netflix, it is the biggest streaming media company in the world. Netflix has the world's leading subscription service for TV shows and movies, and its customers in the United States can stream unlimited TV shows and movies on the internet in real time from their computers and mobile devices. The graphs also show the market's confidence in the corporation. People are more willing to purchase its online goods and services.
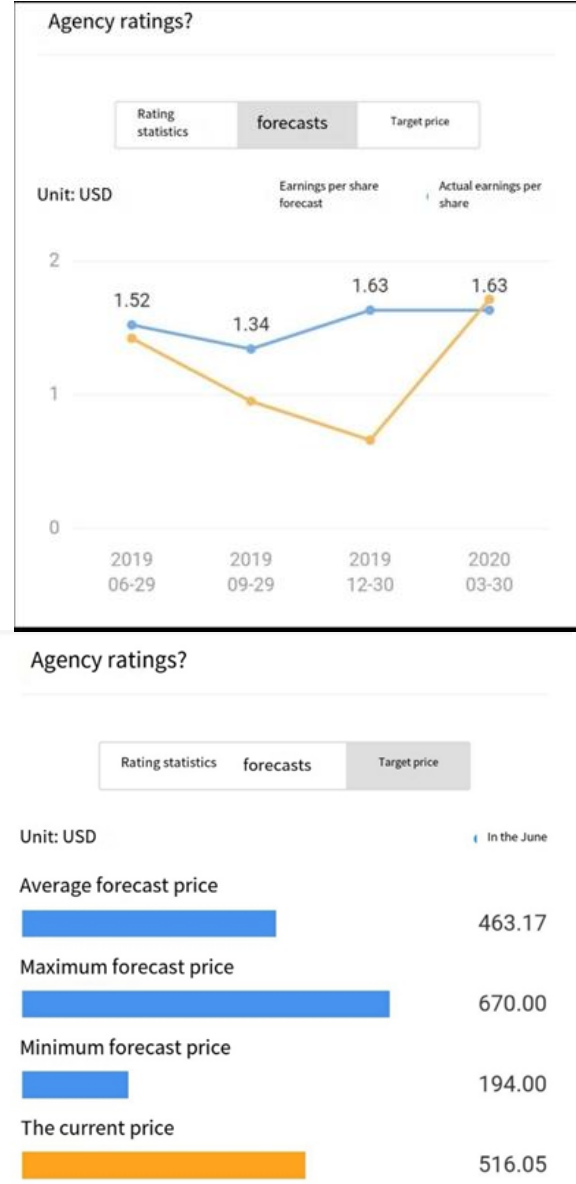

Figure 8. Trend chart for Netflix stock in late September 2020.

So, to sum up, I predict these two stocks will do well in the future. Individual American investors can have a try.

\section{LIMITATIONS}

I have noticed the impact of the systematic risk. Financial risk prevention has always been the core 
content in the development of the financial industry. In particular, systemic financial risks directly affect the healthy and stable development of the entire financial system and economic system. Therefore, the prevention of systemic financial risks is of vital importance.

Systemic risk comes from macro market environment, while non-systemic risk comes from micro individual factors. As long as we participate in the market, systemic risk will be inevitable, while nonsystemic risk can be avoided through risk management means such as portfolio diversification.

Those changing and dynamic factors that I mentioned before are all included in this part. We can do little to avoid the systematic risk. The only way is to try to reduce the influence.

On September 3, the three major U.S. stock indexes fell sharply from their all- 22 time highs and suffered their biggest declines in months, as a broad pullback in technology stocks took hold. Among them, the Dow Jones Industrial Average closed down 810.87 points, or $2.79 \%$, at 28289.63 . The S\&P and NASDAQ fell $3.52 \%$ and $4.96 \%$, respectively.

Shares of tech giant Apple fell 7.93\%. Amazon, Netflix, and Facebook all fell more than $3.7 \%$, and the S\&P 500 technology sector fell more than $5 \%$. This is its first daily limit in 11 trading days and its biggest one-day drop since March.

The US stock market is very, very unstable and changing. Or I mean, the world market is very unstable and dynamic. There are so many flexible factors which will have some awful impact on my study. There are so many political factors that will affect the findings in the report. So, I cannot consider all the possible aspects. Please be careful cautious when you make an investment.

\section{AUTHORS' CONTRIBUTIONS}

The essay is a part of an Undergraduate Program in Finance in University of Cambridge. Deng Siyuan, as an undergraduate from Southwestern University of Finance and Economics, became a registered research student in the Department of Financial Mathematics at St John's College, Cambridge. This paper, completed on October 5, 2020, aims to provide a multi-perspective study on the trend of the U.S. financial market during the epidemic period and provide reference for the risk management field.

\section{ACKNOWLEDGMENTS}

In the process of the essay, many of my beloved friends and teachers have supported me a lot. Here, I sincerely thank them for their hard work.

Research Leader: Matthias Dörrzapf
Supervisor: Yasmin Begum

Institution and Department: University of Cambridge Department of Psychology Integration of Science, Technology and Culture, University of Cambridge ST John's College.

\section{REFERENCES}

[1] Florin ILIE, Considerations Regarding Financial Risk Management in Order to Maximize Earnings Duding the Coronavirus Pandemic(J), BULETIN ŞTIINŢIFIC, Nr.1(49), 2020. DOI: 10.2478/bsaft2020-0004

[2] Ben Mcclure, Explaining the Capital Asset Pricing Model (CAPM), https://www.investopedia.com/articles/06/capm.asp (EB), 2020.

[3] Diana Tashanova, Ainur Sekerbay, Danni Chen, Yuwen Luo, Shuyi Zhao, Qingquan Zhang, Investment Opportunities and Strategies in an Era of Coronavirus Pandemic(D), Gies Business School, University of Illinois at UrbanaChampaign, 2020

[4] Yosef Bonaparte, Pricing the Economic Risk of Coronavirus: A Delay in Consumption or a Recession? (D), University of Colorado at Denver, 2020

[5] Kerstin Lopatta, Kenji Alexander, Laura Gastone, Thomas Tammen, to report or not to report about Coronavirus? The role of periodic reporting in explaining capital market reactions during the COVID-19 pandemic(D), University of Hamburg, Germany, 2020 